\title{
CORREÇÃO CIRÚRGICA DE LÁBIO DUPLO ASSIMÉTRICO: RELATO DE CASO
}

Patrícia dos Santos SOUZA, Fernanda Brasil Daura Jorge BOSS, Joel MOTTA JUNIOR, Glaykon Alex Vitti STABILE

O lábio duplo é um crescimento anormal da mucosa labial presente com maior frequência no lábio superior, tornando-se evidente ao sorrir. Pode interferir na fonética, mastigação e principalmente na estética, causando constrangimento ao paciente. $O$ lábio duplo pode ser de origem congênita ou adquirida por trauma, não tendo prevalência por gênero ou etnia. Este trabalho tem como objetivo abordar as características clínicas dessa condição, formas de tratamento, possíveis erros de técnica, além de apresentar o relato de caso clínico. Paciente do gênero feminino, 46 anos de idade apresentava lábio duplo assimétrico com histórico de trauma crônico por mordiscamento e queixa estética. Por meio do relato da paciente não foi possível determinar se a condição evoluiu em decorrência do trauma ou vice-versa. $O$ procedimento consistiu em plastia labial por excisão controlada de mucosa e submucosa. No pós-operatório evidenciou-se o desaparecimento do lábio duplo, dando à paciente a estética desejada.

Palavras-chave: Lábio duplo; Mucosa; Remoção. 